\title{
DEVELOPMENT OF AN AUTONOMOUS NAVIGATION AGRICULTURAL ROBOTIC PLATFORM BASED ON MACHINE VISION
}

\author{
Ismail Abdelmotaleb ${ }^{1}$, Rashad Hegazy ${ }^{2}$, Zakaria Imara ${ }^{3}$ and \\ Alaa El-Din Rezk ${ }^{4}$
}

ABSTRACT

In Egypt, management of crops still away from what is being used today by utilizing the advances of mechanical design capabilities, sensing and electronics technology. These technologies have been introduced in many places and recorded high accuracy in different field operations. So, an autonomous agricultural robotic platform (ARP) based on machine vision has been developed and constructed. The ARP consisted of two main parts namely; 1) Power transmission and auto-guide system; and 2) Robotic platform. The experiments were carried out at department of agricultural engineering, faculty of agriculture, Kafrelsheikh University during 2014-2015. In this study, the experiments were conducted in laboratory to optimize the accuracy of ARP control using machine vision in term of the autonomous navigation and performance of the robot's guidance system. For evaluation the image processing technique, four different camera resolutions $(1080 \times 1920,1944 \times 2592,2736 \times 3648$, and $3240 \times 4320$ pixels) and three camera' heights $(500,700$ and $1000 \mathrm{~mm})$ have been used to measure the execution time for image processing steps. Flight time of spray droplets has been calculated under three levels of spray height, (70, 100 and $130 \mathrm{~mm})$, three levels of spray pressure $(1,3$ and 5 bar) and three levels of nozzle size, $(1.5,3$ and $5 \mathrm{~mm})$. Also, the effect of changing duty cycle percentage $(D C, \%)$ has been studied to control the speed of the ARP with Pulse Width Modulation (PWM) signals. Different nozzle tip sizes and spray pressures have been used to trace the flow rate variation. Based on the total time consumed in the execution time and droplets flight time, speed of the ARP has been noted

1 Professor, Agric. Eng., Dept., Faculty of Agric., Kafrelsheikh Univ.

${ }^{2}$ Assistant Professor, Agric. Eng., Dept., Faculty of Agric., Kafrelsheikh Univ.

${ }^{3}$ Head Researcher, Agric. Eng. Res. Inst., Dokki-Giza.

${ }^{4}$ Engineer, Plant Protection Res. Inst. (PPRI), Dokki-Giza. 
according to the resolution of camera and its height levels. Results showed that the robotic platform' guidance system with machine vision was able to adequately distinguish the path, resist image noise and give less lateral offset error than the human operators. The average lateral error of autonomous was 2.75, 19.33, 21.22, 34.18 and16.69 mm, while the average lateral error of human operator was 32.70, 4.85, 7.85, 38.35 and $14.75 \mathrm{~mm}$ for straight path, curved path, sine wave path, offset discontinuity, and angle discontinuity respectively. The best execution time of image processing was obtained with the minimum values of the camera resolution at $500 \mathrm{~mm}$ camera height. While, increasing the size of nozzle at same height and spray pressure decreased the flight time. The favorable robotic platform' speeds were obtained at lower values of camera resolutions and wider distances between nozzle and camera.

Keywords: Autonomous robotic, machine vision, image processing, Hough transform.

\section{INTRODUCTION}

$\mathrm{M}$ achine vision is the technology to replace or complement manual inspections and measurements with digital cameras and image processing. Machine vision had emerged with the high effectiveness and success in the development of agriculture and industrial areas. Machine vision works basically in four steps: 1) imaging, 2) processing and analysis, 3) communication and 4) action. The applications of machine vision can be classified according to the industries i.e. automotive, electronics, food, logistics, manufacturing, robotics, packaging, pharmaceutical, steel \& mining and wood industry (Patel et al. 2013). A typical machine vision system executes the following processes in the specified order: image capture and enhancement, segmentation, feature extraction, matching features to models, exploitation of constraints and image cues to recover information lost during image processing, and application of domain knowledge to recognize objects in the scene and their attributes (Forsyth and Ponce, 2003). Three main groups of field operations for an autonomous technology were identified: crop establishment, plant care and selective harvesting. To perform these tasks, a designed system must fulfill some 
requirements e.g. light weight, small autonomous machines, computational and energetic autonomy, machine intelligence, external behavior, communication, weather, vehicle system architecture, graceful degradation, self-awareness, management, economics and mechanization tasks (Blackmore et al. 2007). The need for such systems is driven by increasing financial cost on farmers combined with public concern about the environment and working conditions. Efficient deployment of autonomous robotic platforms in the field will allow to care and management of crops in a very different way from what is known today (Blasco et al., 2002; Cho et al., 2002). Robotic platforms and implements may sense and manipulate the crop and its environment in a precise manner with minimal amount of materials and energy making them potentially more efficient than traditional machinery. Image acquisition procedure and image segmentation are critical steps in morphology-based weed and plant identification systems, because highquality images provide important leaf shape information for the feature extraction and plant classification procedures (Meyer and Neto, 2008). Hough transform has been used effectively in many studies for straight line recognition of crop or tree rows using vision or/and laser scanner as navigation sensor (Ayala et al., 2008; Barawid et al. 2007; Gao et al. 2010; Hamner et al. 2010 and Torres-Sospedra and Nebot, 2011). Ji and Qi (2011) reported that Hough transform is slow due to the huge computation, they proposed a randomized Hough transform to reduce computational time. Some modifications have been proposed to improve the Hough transformation which is applied only to those points which are edge points along the crops. But this requires the application of techniques for edge extraction. Astrand and Baerveldt (2005) used a method for robust recognition of plant rows based on the Hough transform that is able to guide agricultural machines. The novelty of their algorithm was that they modeled a plant row with a rectangular box instead of a line. So, the main objectives of the present study are to developed ARP for plant identification and distinguish it from weeds with measuring the performance of the robot's guidance, and to evaluate the system under different variables for inter-row autonomous navigation. 


\section{MATERIALS AND METHODS}

\section{Experiments and robotic platform components}

Manufacturing of the ARP and the experiments were conducted at Department of Agricultural Engineering, Faculty of Agriculture, Kafrelsheikh University during 2014 and 2015. The ARP consisted of two main parts namely; 1) Power transmission and auto-guide system; and 2) Robotic platform. The main specifications of the ARP are summarized in Table 1, while the main components of the ARP were illustrated in Figures 1 and 2. Experiments were conducted to optimize the accuracy of ARP control using machine vision in term of the autonomous navigation and performance of the robot's guidance system. Where, five different row situations (paths); straight path; sin wave path; offset discontinuity path; angel discontinuity path; and curved path have been used in tests. For evaluation the image processing technique, four different camera resolutions $(1080 \times 1920,1944 \times 2592,2736 \times 3648$, and $3240 \times 4320$ pixels $)$ and three camera' heights $(500,700$ and $1000 \mathrm{~mm}$ ) have been used to measure the execution time for image processing steps. Flight time of spray droplets has been calculated under three levels of spray height, (70, 100 and $130 \mathrm{~mm}$ ), three levels of spray pressure (1, 3 and 5 bar) and three levels of nozzle size, $(1.5,3$ and $5 \mathrm{~mm})$. Also, the effect of changing duty cycle percentage (DC, \%) has been studied to control the speed of the ARP with Pulse Width Modulation (PWM) signals. Different nozzle tip sizes and spray pressures have been used to trace the flow rate variation. Based on the total time consumed in the execution time and droplets flight time, speed of the ARP has been noted according to the resolution of camera and its height levels.

\section{Machine vision}

The Arduino $\mathrm{C}$ and Roboreleam programs were used for ARP control and algorithm development. Machine vision operation can be described by four-steps: 1) imaging: take an image, 2) image processing: image processing to obtain a result, 3) communication: send the result to the system in control of the process, 4) action: take action depending on the vision system's results (SICK IVP, 2006) as shown in Figure 3. 


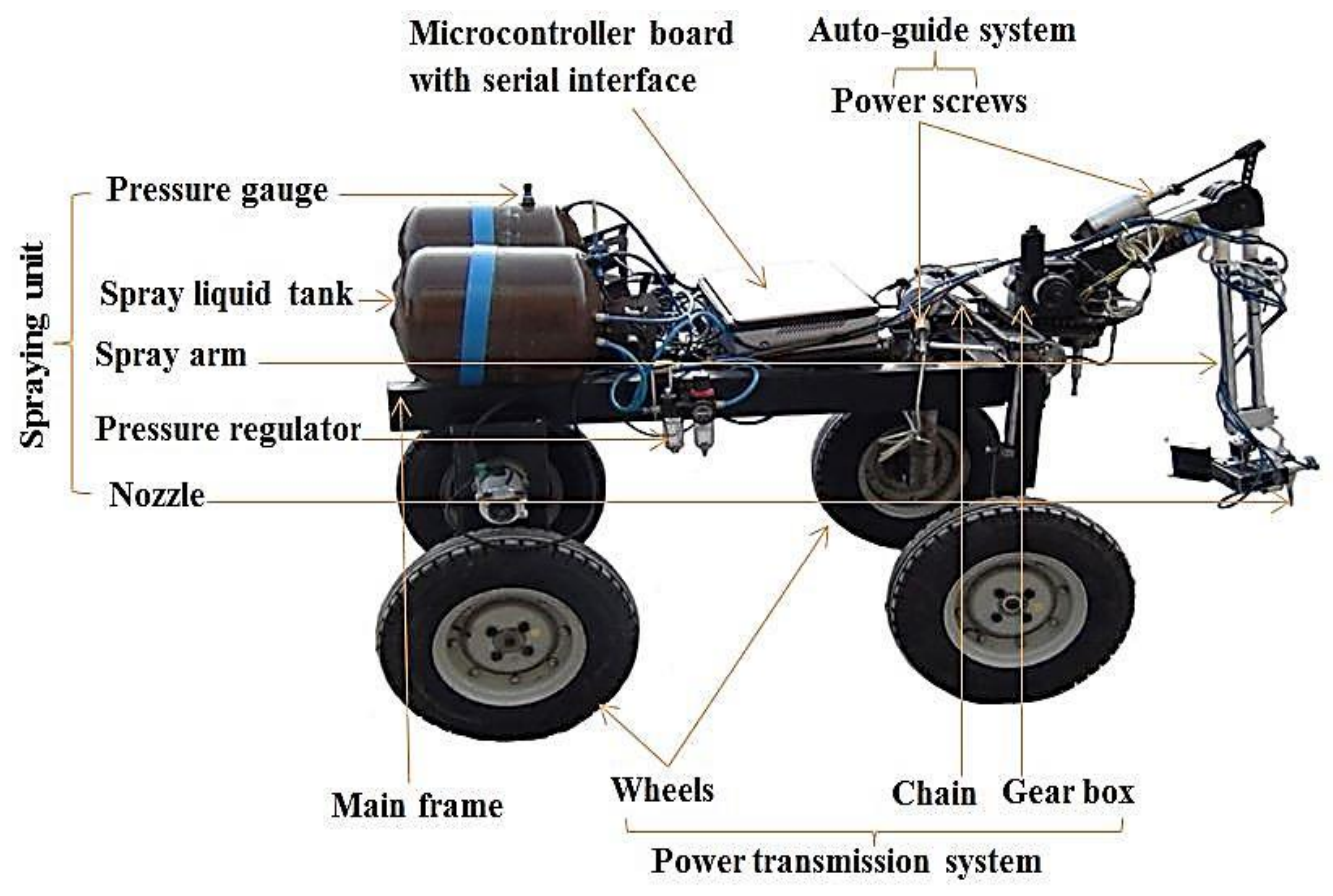

Figure 1: Main components of ARP

\subsection{Image processing techniques (algorithms)}

Hundred images were captured in location of the experiment before image processing step. A computer Pentium Dual-core, $220 \mathrm{GHz}$ and ROBORELEAM version 2.67.10 was used for image processing to develop algorithm. The images were decomposed to red, green and blue layers. The green channel was used for segmentation because the images contained robe of green color. The image processing steps are shown in Figure 4 and described in more detail in this section. The image histogram was calculated, and a threshold was chosen manually based on the image histogram, choosing the value that separates two curves, where one represented the green robe pixels and the other one represented the background pixels. A binary image was produced based on the histogram threshold. This histogram provides us with a view of the images depending on where the view histogram is inserted into the processing step. A histogram is a graphical display of the number of pixels at that intensity (the $\mathrm{Y}$ or vertical axis) with the pixel value or the green color intensity (the $\mathrm{X}$ or horizontal axis 0-255). 

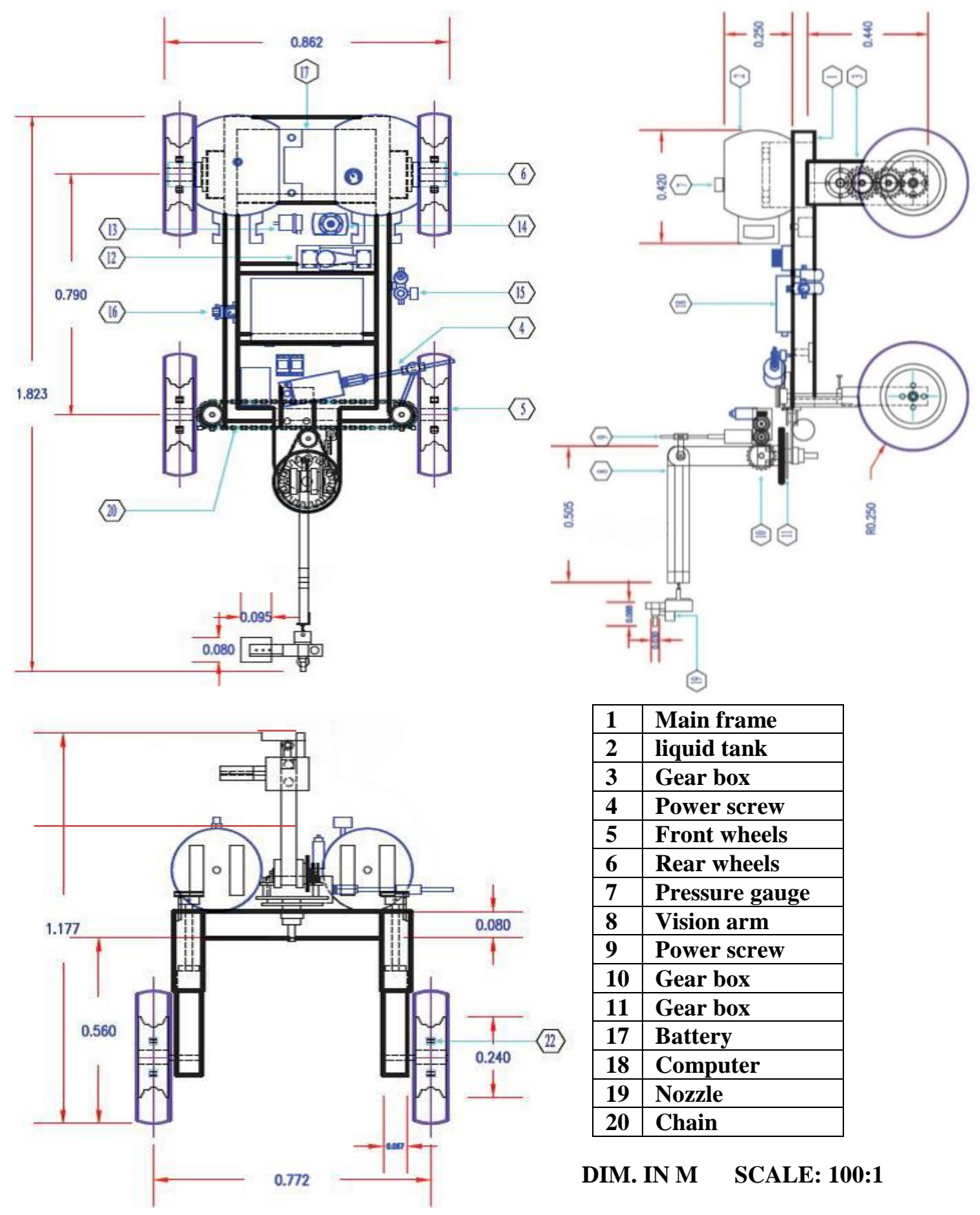

\begin{tabular}{|l|l|}
\hline 1 & Main frame \\
\hline 2 & liquid tank \\
\hline 3 & Gear box \\
\hline 4 & Power screw \\
\hline 5 & Front wheels \\
\hline 6 & Rear wheels \\
\hline 7 & Pressure gauge \\
\hline 8 & Vision arm \\
\hline 9 & Power screw \\
\hline 10 & Gear box \\
\hline 11 & Gear box \\
\hline 17 & Battery \\
\hline 18 & Computer \\
\hline 19 & Nozzle \\
\hline 20 & Chain \\
\hline
\end{tabular}

DIM. IN M SCALE: 100:1

Figure 2: Schematic drawing of the ARP 
Table 1: Specification of ARP

\begin{tabular}{|c|c|c|c|}
\hline \multicolumn{4}{|c|}{ specifications } \\
\hline \multicolumn{3}{|c|}{ Overall length $\quad(\mathrm{mm})$} & 1250 \\
\hline \multicolumn{3}{|c|}{ Overall width $\quad(\mathrm{mm})$} & 860 \\
\hline \multicolumn{3}{|c|}{ Overall height $\quad(\mathrm{mm})$} & 1177 \\
\hline & 560 \\
\hline \multicolumn{2}{|c|}{\begin{tabular}{l|l}
\multicolumn{2}{|c|}{ Ground clearance $(\mathrm{mm})$} \\
Power
\end{tabular}} & \multirow{2}{*}{$\frac{\text { capacity }}{\text { Voltage }}$} & $12 \mathrm{~V}, 70 \mathrm{~A} / \mathrm{h}$ \\
\hline \multirow{8}{*}{$\begin{array}{l}\text { Power } \\
\text { transmission }\end{array}$} & \multirow{3}{*}{$\begin{array}{l}\text { Two DC } \\
\text { brushed } \\
\text { motors }\end{array}$} & & $12 \mathrm{~V}$ \\
\hline & & Revolutions & $4000 \mathrm{rpm}$ \\
\hline & & Max. output & 150 watt \\
\hline & \multirow{4}{*}{$\begin{array}{l}\text { Two circuits } \\
\text { for two rear } \\
\text { wheels }\end{array}$} & Type and model & $\begin{array}{l}\text { Single MegaMoto H- } \\
\text { bridge mode }\end{array}$ \\
\hline & & applied input & Pulse-width modulation \\
\hline & & PWM frequency & $\mathrm{DC}-20 \mathrm{kHz}$ \\
\hline & & Voltage Range & $6 \mathrm{~V}-24 \mathrm{~V}(28 \mathrm{~V}$ ab. $\max )$ \\
\hline & \begin{tabular}{|l} 
Two gear box \\
\end{tabular} & Velocity ratio & $76.40 \mathrm{rpm}$ \\
\hline \multirow{9}{*}{$\begin{array}{l}\text { Auto-guide } \\
\text { system }\end{array}$} & \multirow{3}{*}{$\begin{array}{l}\text { DC brushed } \\
\text { motors }\end{array}$} & Voltage & $12 \mathrm{~V}$ \\
\hline & & Current & $20 \mathrm{~A}$ \\
\hline & & Revolutions & $1500 \mathrm{rpm}$ \\
\hline & & Type and model & acme thread \\
\hline & Dowron cansu & Screw length & $240 \mathrm{~mm}$ \\
\hline & Fower screw & diameter & $10 \mathrm{~mm}$ \\
\hline & & The nut length & $50 \mathrm{~mm}$ \\
\hline & $\begin{array}{l}\text { Magnetic } \\
\text { relay }\end{array}$ & & $30 \mathrm{~A}$ at $12 \mathrm{VDC}$ \\
\hline & Micro switch & Voltage & $12 \mathrm{VDC}$ \\
\hline \multirow{6}{*}{$\begin{array}{l}\text { Robotic } \\
\text { platform }\end{array}$} & Software & $\begin{array}{l}\text { Roboreleam } \\
\text { Arduino C }\end{array}$ & Version 2.67.10 \\
\hline & Software & Arduino C & Version 1.0.3 \\
\hline & \multicolumn{2}{|l|}{ Microcontroller } & ATmega328 \\
\hline & \multicolumn{2}{|c|}{ Operating Voltage } & $5 \mathrm{~V}$ \\
\hline & Digital I/O Pin & & $\begin{array}{l}14 \text { (of which } 6 \text { provide } \\
\text { PWM output) }\end{array}$ \\
\hline & Flash Memory & & $\begin{array}{l}32 \mathrm{~KB} \text { (ATmega328) of } \\
\text { which } 0.5 \mathrm{~KB} \text { used by } \\
\text { bootloader }\end{array}$ \\
\hline & Camera & & $\begin{array}{l}\text { Sony Handycam HDR- } \\
\text { CX580V, } 20.4 \text { pixels }\end{array}$ \\
\hline Robotic & & $\mathrm{CPU}$ & Pen. Dual-core $220 \mathrm{GHz}$ \\
\hline & Computer & Memory & 4GB DDR3 \\
\hline & & Storage & $250 \mathrm{~GB}$ \\
\hline
\end{tabular}




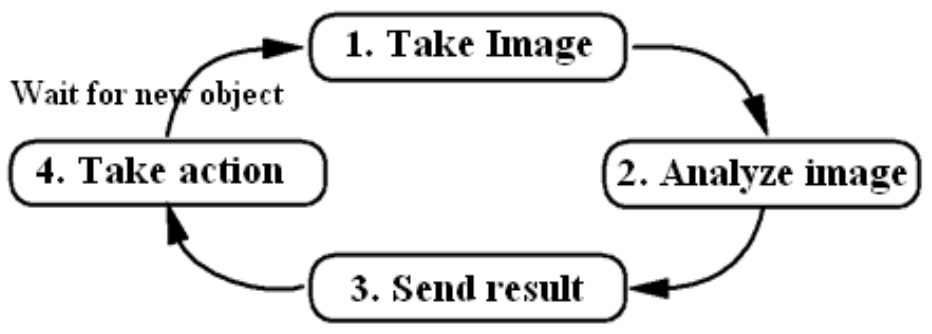

Figure 3: Stages of machine vision operation

Using a histogram images, we can quickly see luminance and the pixel (RGB) color distribution for green robe as shown in Figure 5. Original image is shown in Figure 6 (A). Depending on the green color, RGB filter will diminish all pixels that are not of green color. The following function will diminish white pixels even though they may contain the green color according to the following order of the program:

$$
\mathbf{G}=[[\mathbf{G}-\mathbf{B}]+[\mathbf{G}-\mathbf{R}]], \mathbf{R}=\mathbf{0}, \mathbf{B}=\mathbf{0}
$$

$\mathrm{G}$ is then normalized with respect to the maximum green value, $\mathrm{B}$ and $\mathrm{R}$ is blue and red color value. Based on the above formula it can be seen that white pixels result in a zero value whereas pure primary colors $(\mathrm{G}=255$, $\mathrm{R}=0, \mathrm{~B}=0) \mathrm{G}$ doubles its value. Threshold value of color allows us to specify a minimum value below which pixels are considered to be black and will be ignored when calculating the image results, it's important to distinguish the soil from plants and weeds by ignorance of the soil information from image Figure 6 (B).

The border module extracts the outline or border of a binary black and white image. The background is assumed to be black whereas the foreground image (robe) is non-black pixels. Note that the extracted border is the border within the image Figure 6 (C). Detection module will recolorize plant border with the green color. This module is useful for inspection or illustration of detected plant that can then be colored into an obvious color to be overlayed with the original image (robe green) as shown Figure 6 (D). 


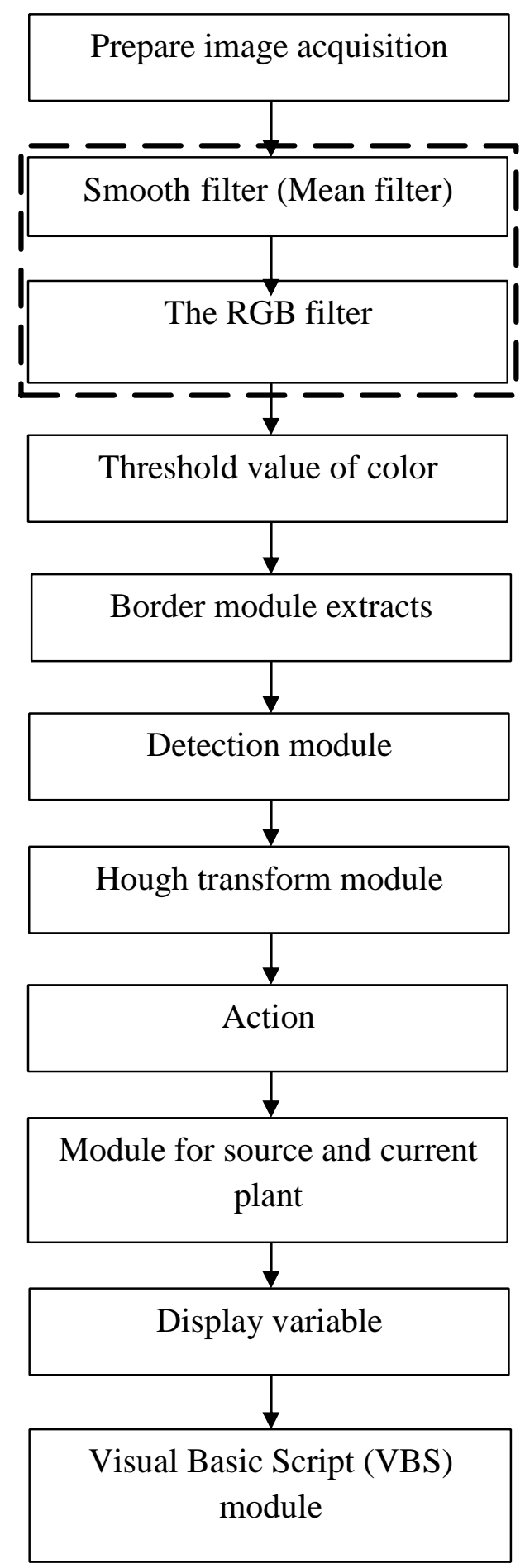

Figure 4: Image processing steps 

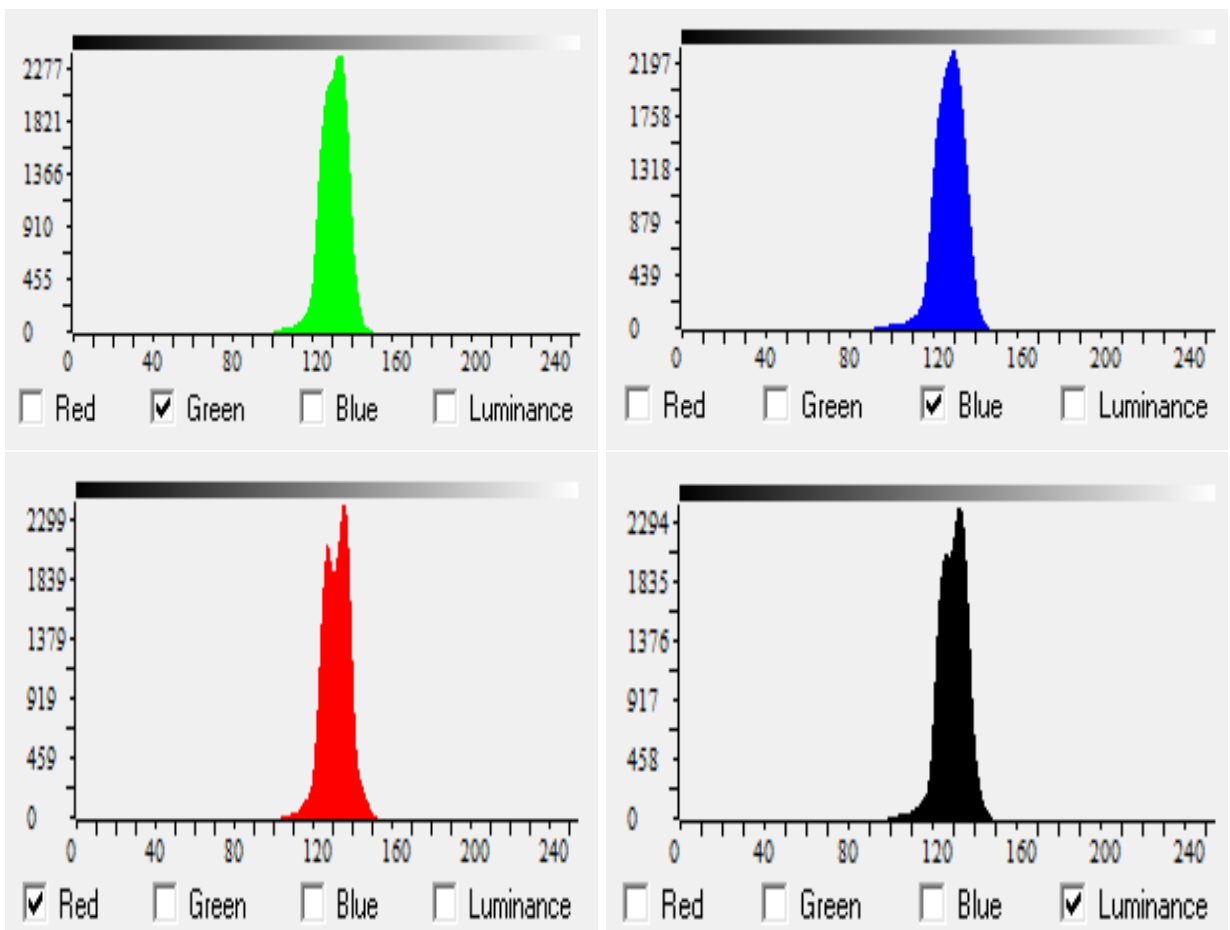

Figure 5: The pixel color distribution of RGB color

\subsection{Hough transform module}

The Hough Transform application is typically used as a line detection method through mathematical transformation. The Hough transform is a technique for creating lines based on points. The Hough transform takes as input many points and will generate guesses for what lines those points represent. The task of detecting lines now instead becomes a task of detecting peaks within this image (Figure 7 (1-A) and (2-A)). Figure 7 illustrate steps of rows detection using Hough transform.

\section{Accuracy of ARP control using machine vision.}

\subsection{Performance measures of the robot's guidance system}

Several different tests were set up to simulate the conditions the vehicle might encounter during its autonomous operation. Five testing situations [a straight line $40 \mathrm{~m}$ with no curves, a $40 \mathrm{~m}$ curve of $5 \mathrm{~m}$ separating the highest point in the curve (peak from the original straight line), a $40 \mathrm{~m}$ sine wave of amplitude $5 \mathrm{~m}$ and period $25 \mathrm{~m}$, a $20 \mathrm{~m}$ straight line offset 
discontinuity, and a $20 \mathrm{~m}$ straight line angle discontinuity $\left(120^{\circ}\right)$ ] as shown in Figure 8 and according to Spencer (2004).

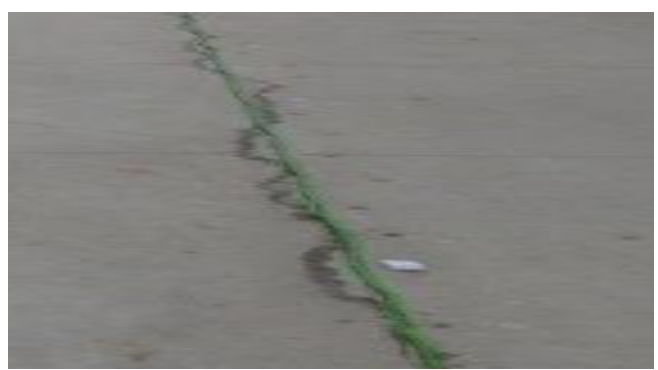

(A)

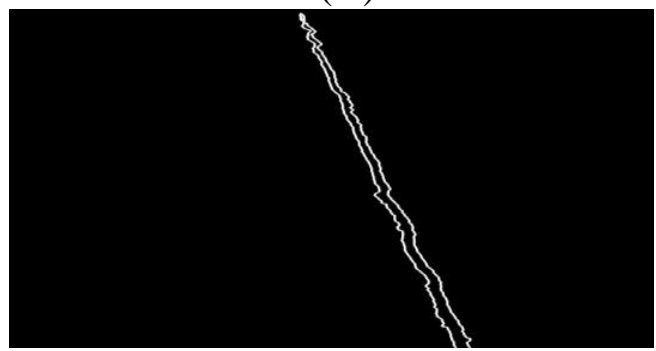

(C)

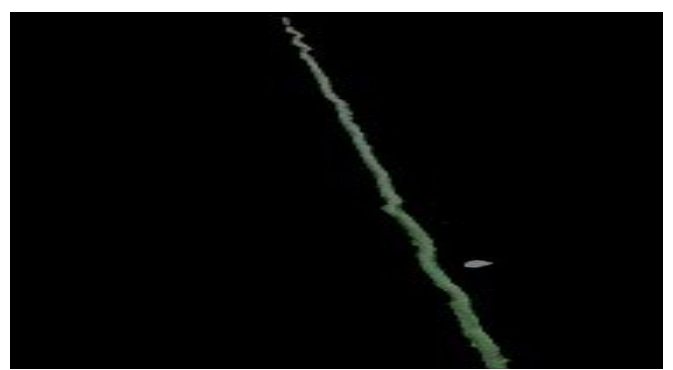

(B)

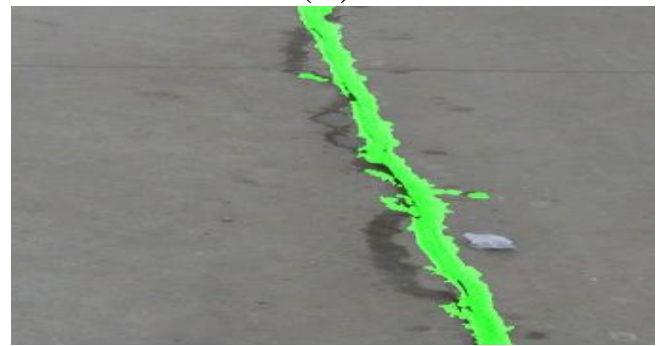

(D)

Figure 6: Stages of image processing for robe recognition

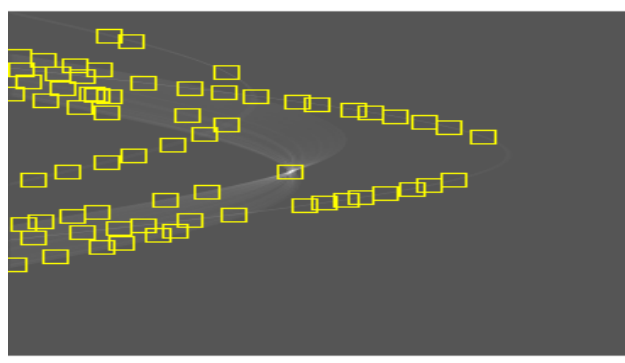

1-(A) Hough accumulator space

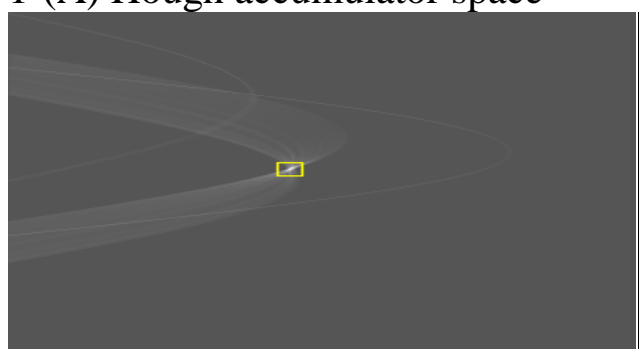

2-(A) Hough accumulator space

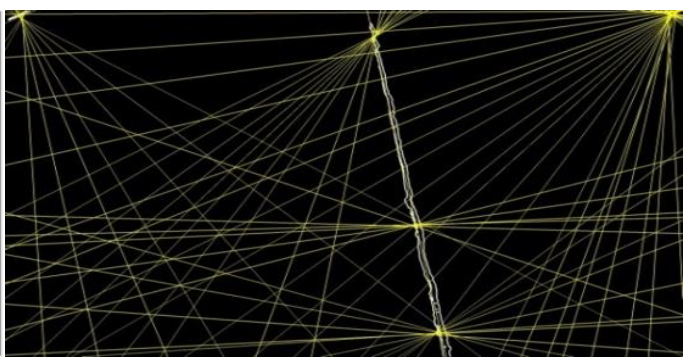

1-(B) Detection of rows

Figure 7: Detection of rows using Hough transform method 
Straight line

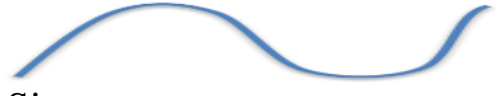

Sine wave
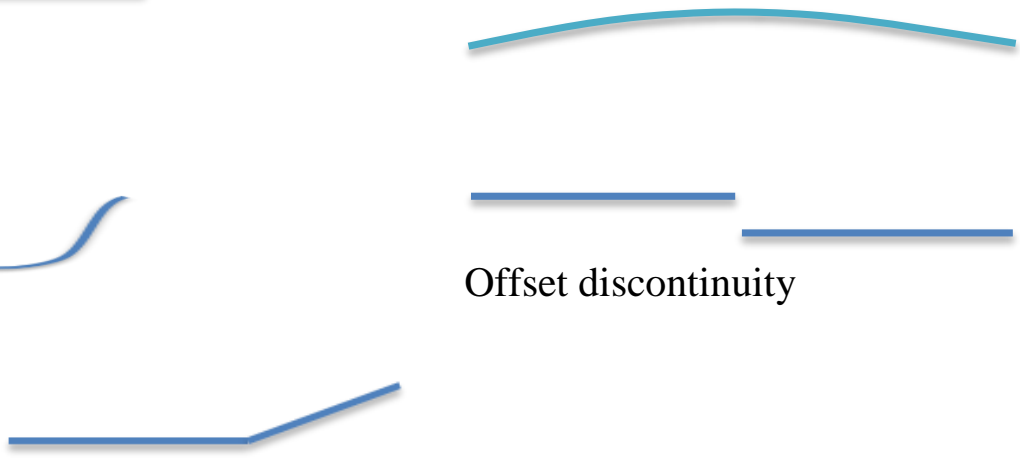

Angle discontinuity

Figure 8: Illustration of the five different test situations

Four autonomous test repetitions were run for each test situation to provide statistically valid results compared to one human operator trial. Liquid tank was used with a spout (method of regulating the flow of water from the tank). Just prior to a test, the water would be allowed to drip steadily from the tank at a rate that would provide a near-continuous record of the robot location Figures 9 and 10. The spout was placed directly between the rear wheels at the center of rotation of the vehicle to gather the best possible measurement of the location. During autonomous operation the water would drip along the path taken by the vehicle. When the trial was complete, the data collector was able to read measurements from the green robe to the water droplets line by a ruler at each of the $1 \mathrm{~m}$ markings along length of the test path. In Figure 11, the flowchart of autoguide system for ARP is presented:

\subsection{Inter-row autonomous navigation and response time for plant identification}

The lateral offset error is represented in three different ways to describe the performance of the system. The average lateral error, maximum lateral error, and standard deviation of the error are reported. The average lateral error is an indicator of the overall error of the system, the maximum lateral error indicates the largest error that occurred, which is important to consider since certain applications would only allow a certain amount of error. The standard deviation indicates the variability of 
the motion of the agricultural robot. The standard deviation $(\delta)$ was expressed according to ASAE standard (1998), as below:

$$
\delta=\sqrt{\frac{\sum\left(\mathrm{x}_{\mathrm{i}}-\overline{\mathrm{x}}\right)^{2}}{\mathrm{n}-1}}
$$

Where: $\delta$ is the standard deviation, $x_{i}$ represents each value in the line, $\bar{x}$ is the mean of the value, and $\mathrm{n}$ is number of measurements.

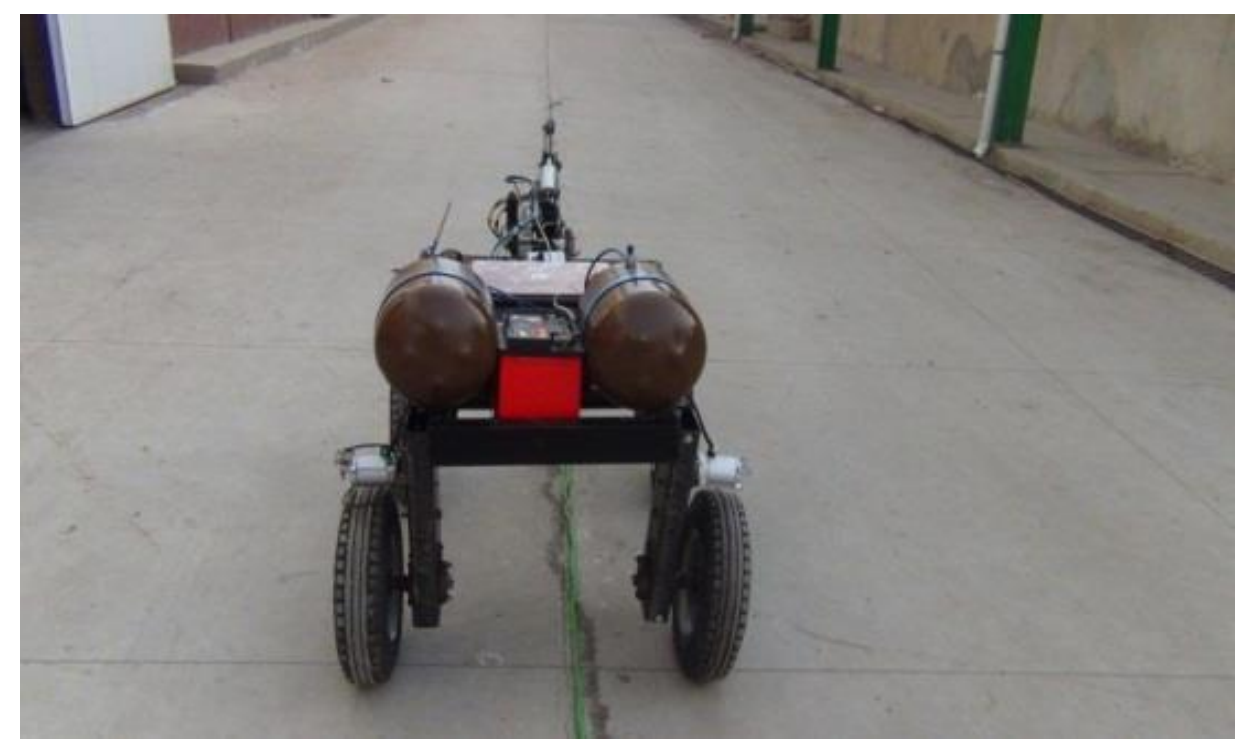

Figure 9: Dripping along green straight line

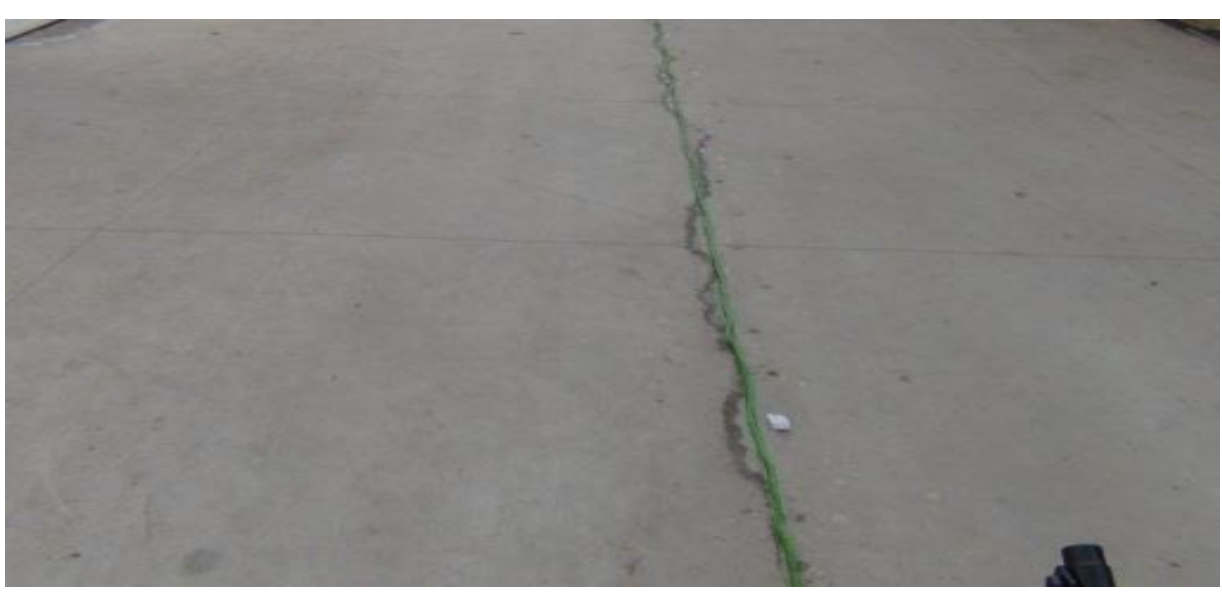

Figure 10: Straight line test of ARP 


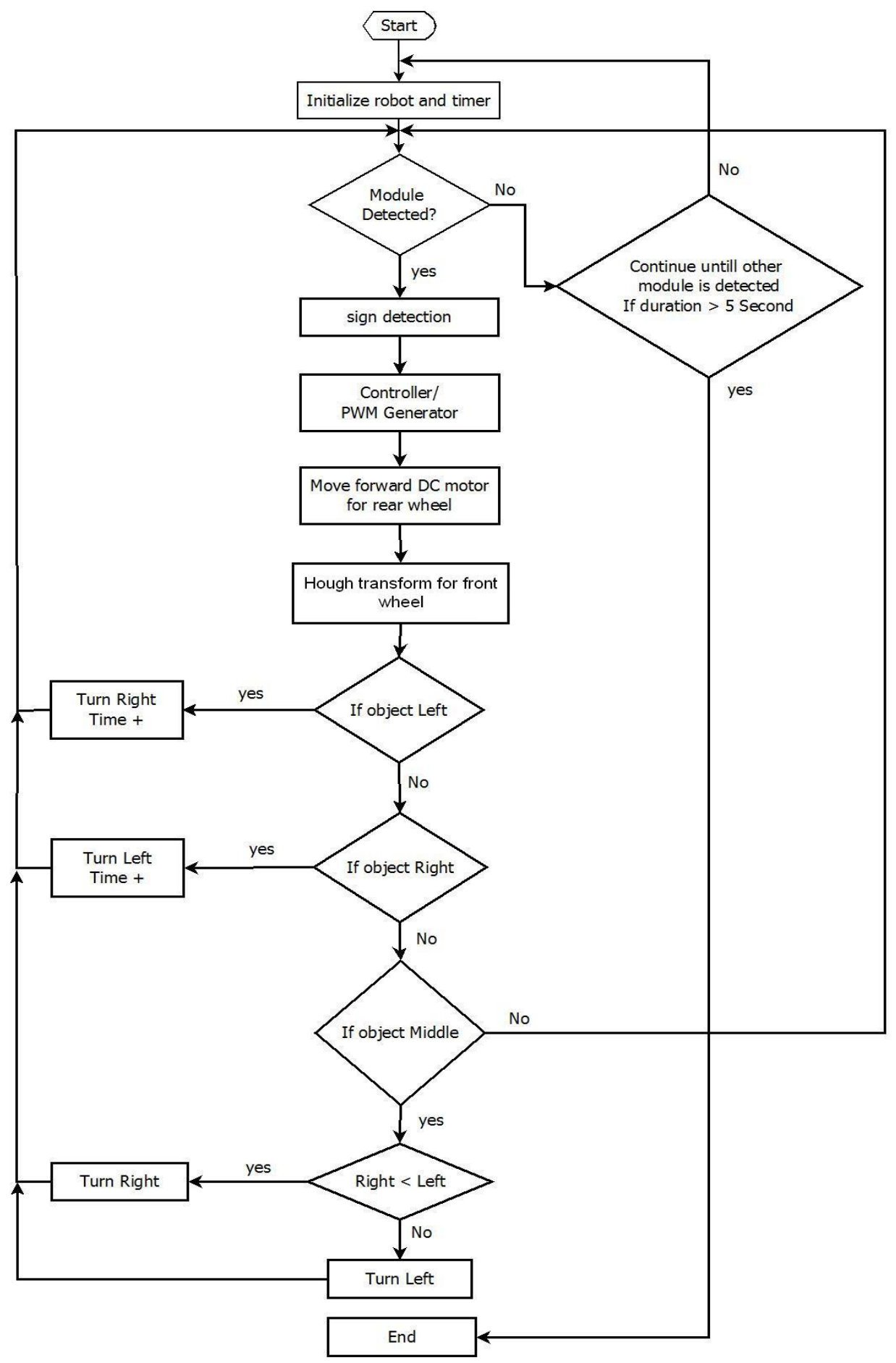

Figure 11: Flowchart for auto-guide system 


\subsubsection{The flight time of a spray droplet}

Exit velocity using accelerometer used to get the flight time of a spray droplet for a pre-measured distance (Figure 12). A valve was positioned above an accelerometer, model (ACH-01, Pennwalt crop., Kynar piezo Film Dept., Vallery Forge, PA.) at a height 70, 100, $130 \mathrm{~mm}$. when a spray droplet hit the accelerometer, the output signal was amplified by model (IB-ACH01-01, Pennwalt crop., Vallery Forge, PA) and displayed on one channel of an oscilloscope model (TEKTRONIX K213). Then, the flight time from valve opening to the time the droplet hit the accelerometer was read from the oscilloscope. The flight time measurement was carried out under the study parameters at different levels of pressure 1, 3 and $5 \mathrm{bar}$ and nozzle size 1.5, 3.0 and $5 \mathrm{~mm}$, according to lee (1998).

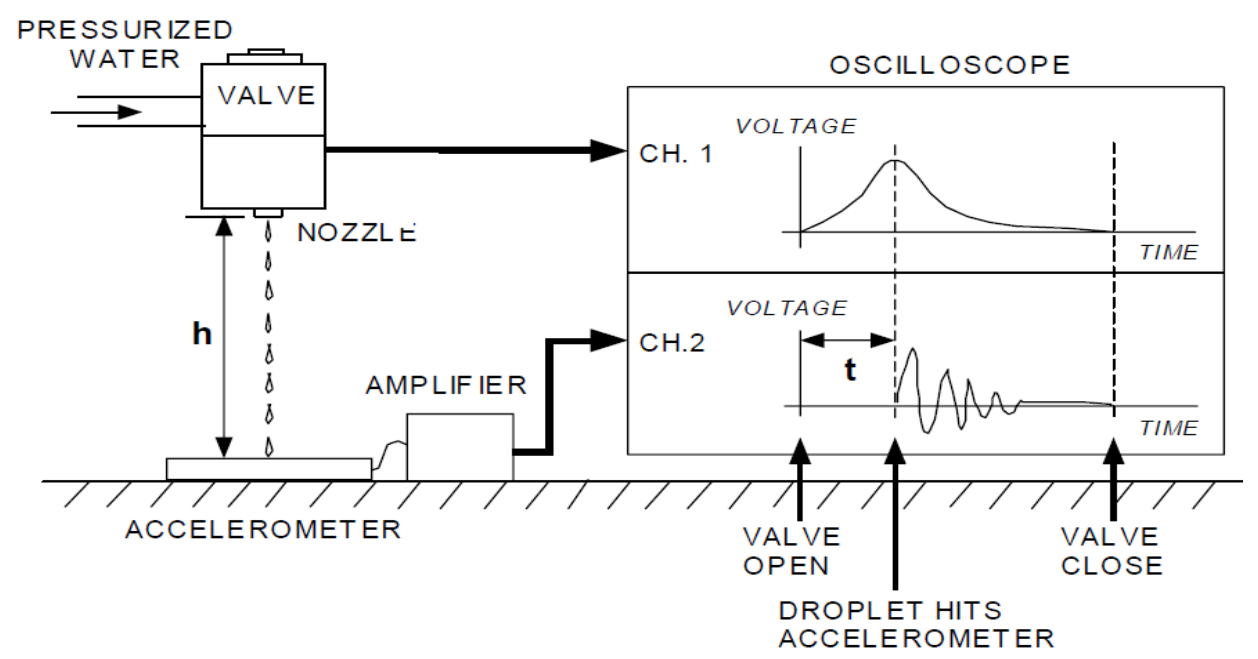

Figure 12: A schematic for measuring an exit velocity of spray droplet

\subsubsection{Total response time}

The total response time $\left(\mathrm{T}_{\mathrm{RS}}\right.$ ) can be defined as the sum of the individual periods of time elapsing during each step of the online application process. In our case there are only two time components, the first component is acquisition time $\left(\mathrm{T}_{\mathrm{A}}\right)$ which is the time required for the detection and recognition of the bean plant. The second component of total response time $\left(\mathrm{T}_{\mathrm{RS})}\right.$ is the response time of the injection metering 
system $\left(T_{R}\right)$ which is the time required for the injection spray nozzle according to Hloben (2007).

$$
\mathbf{T}_{\mathrm{RS}}=\mathbf{T}_{\mathrm{A}}+\mathbf{T}_{\mathbf{R}}
$$

\subsubsection{Calculation of forward speed for the ARP}

There is a constant distance $\left(l_{s}\right)$ between the camera and the nozzles (spray boom). This distance is divided by the forward speed of the machine to give total response time. The relation between these variables described by Hloben (2007), where:

$$
\mathbf{T}_{\mathrm{RS}} \leq \frac{\mathbf{l}_{\mathbf{s}}}{\mathbf{U}}
$$

Where, $T_{R S}$ is total response time of the application system in $s, 1_{s}$ is distance between center of camera and nozzle tip in $\mathrm{m}$, and $\mathrm{U}$ is the forward speed, $\mathrm{m} \mathrm{s}^{-1}$

\subsection{PWM signal control on DC motor of rear wheel}

Pulse Width Modulation (PWM) signals were used to control speed of the ARP making possible changing of voltage at frequency $500 \mathrm{~Hz}$. The PWM duty cycle was defined as on/off $(\%)$ in one period. Changing the duty cycle of the PWM signals controlled the open time of DC motor, and thus altered its speed and voltage.

The process in which the switch cycle $(\mathrm{T})$ is unchanged and the switch turn-on time $\left(\mathrm{t}_{\mathrm{on}}\right)$, which is adjusted, is called Pulse-Width Modulation (PWM), where $t_{\text {off }}$ is the turn-off time of the output voltage (Figure 13) (Wang and Huang, 2000).

Conduction duty cycle (d) can be calculated using below equation:

$$
\mathrm{d}=\frac{\mathrm{T}_{\mathrm{ON}}}{\mathrm{T}}
$$

The average output voltage, Vo cab be calculated as described by Obed and Basheer (2011) and as below equation

$$
\mathrm{V}_{\mathrm{o}}=\frac{\mathrm{T}_{\mathrm{ON}}}{\mathrm{T}}=\mathrm{d} \mathrm{V}_{\mathrm{dc}}
$$

Where, $\mathrm{V}_{\mathrm{dc}}$ is the supply voltage. 


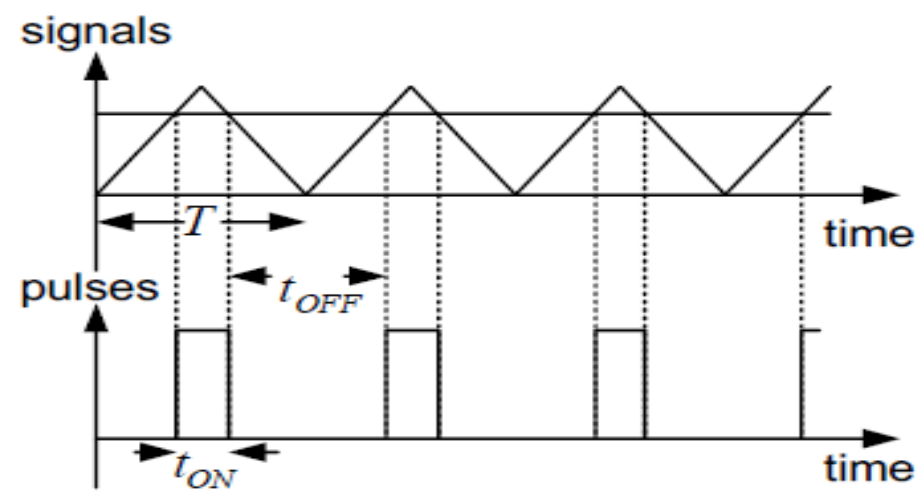

Figure 13: PWM pulses of DC motor

\section{RESULTS AND DISCUSSION}

\section{Accuracy of ARP control using machine vision}

\subsection{Autonomous navigation}

An autonomous ARP was developed and tested to assess the performance of the system. Data was collected for five different row situations with four autonomous trials and one human trial. The results assess the performance of the system in two ways: How well the vehicle follows the identified line, and how well the machine vision system identifies the line.

\subsubsection{Performance measures of the robot's guidance system.}

Since +/- two standard deviations from the mean represents $95 \%$ of the data in a set, the standard deviation in this case can be thought of as, "the vehicle was within this distance of the average lateral error $95 \%$ of the time." Even though successful line following implies successful row identification.

\subsubsection{The straight line situation}

Table 2 showed that the overall maximum lateral error of autonomous for the straight test situation was $84.75 \mathrm{~mm}$, the average lateral error was 2.75 $\mathrm{mm}$, and the standard deviation was $45.56 \mathrm{~mm}$. It should be noted that the average lateral error was near zero, though it simply indicates that in straight line following there is no constant error in the system, or the system does not favor one direction over another. In each of the individual straight line trials the average lateral error was near zero, though not zero. The largest errors tended to occur in the first 20 meters of the trials. The standard deviation of the human operator was $34.07 \mathrm{~mm}$, 
the average lateral error was $32.70 \mathrm{~mm}$ and maximum lateral error was $85.00 \mathrm{~mm}$, concerning the maximum lateral error, the autonomous control did slightly better than human operator by $0.25 \mathrm{~mm}$. Figure 14 indicated that the largest errors tended to occur in the first $20 \mathrm{~m}$ in trail 2, while the largest error in human operator was slightly better than the autonomous control. These results are in the same line with those found by Xue et al., (2012) and Kiani and Jafari (2012) also in a great harmony with those reported by spencer (2004).

Table 2: Statistical summary for comparison human performance to autonomous control for different test situations.

\begin{tabular}{|l|c|c|c|c|}
\hline \multirow{2}{*}{ Test Situation } & Control & $\begin{array}{c}\text { Average } \\
\text { Lateral } \\
\text { error, mm }\end{array}$ & $\begin{array}{c}\text { Maximum } \\
\text { Lateral } \\
\text { error, mm }\end{array}$ & $\begin{array}{c}\text { Standard } \\
\text { Deviation, } \\
\text { mm }\end{array}$ \\
\hline \multirow{3}{*}{ Straight Path } & Autonomous & 2.75 & 84.75 & 45.56 \\
\cline { 2 - 5 } & Human & 32.70 & 85.00 & 34.07 \\
\hline \multirow{2}{*}{ Curved Path } & Autonomous & 19.33 & 106.00 & 63.30 \\
\cline { 2 - 5 } & Human & 4.85 & 77.00 & 51.72 \\
\hline \multirow{2}{*}{ Sine Wave Path } & Autonomous & 21.22 & 148.50 & 93.20 \\
\cline { 2 - 5 } & Human & 7.85 & 128.00 & 64.37 \\
\hline \multirow{2}{*}{$\begin{array}{l}\text { Offset } \\
\text { Discontinuity }\end{array}$} & Autonomous & 34.18 & 120.50 & 64.50 \\
\cline { 2 - 5 } & Human & 38.35 & 90.00 & 57.40 \\
\hline \multirow{2}{*}{$\begin{array}{l}\text { Angle } \\
\text { Discontinuity }\end{array}$} & Autonomous & 16.69 & 94.25 & 59.35 \\
\cline { 2 - 5 } & Human & 14.75 & 70.00 & 47.86 \\
\hline
\end{tabular}

\subsubsection{The curved line situation}

Lateral error is continuously being introduced to the system due to the constant radius of the curve. The overall maximum lateral error of autonomous control for the curved line test situation was $106.00 \mathrm{~mm}$, the average lateral error was $19.33 \mathrm{~mm}$, and the standard deviation was 63.30 $\mathrm{mm}$. Both the maximum lateral error and the standard deviation of curved tests were higher than the straight line test situation. The maximum lateral error of autonomous control was increased by $21.25 \mathrm{~mm}$ and was higher than the human operator performance by $29.00 \mathrm{~mm}$ in curved line test 
situation. Due to the curved path, Figure 15 does not allow us to observe many notable features beyond the oscillation of the vehicle. It can be noted that a given trial tends to error on one side more than the other in the curved trials, when this was not the case in the straight trials (Figure 15). In autonomous control, the maximum lateral error and average lateral error were 106.00 and $19.30 \mathrm{~mm}$ where they were 77.00 and $4.85 \mathrm{~mm}$ respectively in human operator, the standard deviation in autonomous control was slightly higher than the human operator by $11.58 \mathrm{~mm}$. The results are in agreement with those obtained by Subramanian (2005) and spencer (2004).

\subsubsection{Sine wave test}

In this case the radius of the curves was changing in value and direction. This is an atypical operation and a task that is more demanding on the system than the straight line or curved test, but a good test of the system's robustness. The overall maximum lateral error for the sine wave test situation was $148.5 \mathrm{~mm}$ in autonomous control where it was $128.00 \mathrm{~mm}$ in human operator, the average lateral error was $21.22 \mathrm{~mm}$, and $7.85 \mathrm{~mm}$ for autonomous control and human operator respectively, and the standard deviation was $93.20 \mathrm{~mm}$ while it was $64.40 \mathrm{~mm}$ in the human operator. The test statistics indicate significantly less accurate performance on the more difficult test situation. Large errors approaching $150 \mathrm{~mm}$ would be undesirable, they are unacceptable in certain applications as spray precision. Though the autonomous performance was not as good as other test situation, the human operator performance indicates the difficulty of the course. The human operator performed slightly better than the autonomous control, but overall there were no significant differences between the two cases as confirmed by Spencer (2004).

\subsubsection{The line offset discontinuity}

Line offset discontinuity consisted of a step function introduced in the line path at the 11 meter point into the run .The overall maximum lateral error for line offset discontinuity test situation was $120.50 \mathrm{~mm}$, the average lateral error was $34.18 \mathrm{~mm}$, and the standard deviation was 64.50 $\mathrm{mm}$ in the autonomous control (Table 2). 


\subsubsection{The angle discontinuity test}

A ramp function was introduced into the test path. In this situation, the overall maximum lateral error was $94.25 \mathrm{~mm}$, the average lateral error was $16.69 \mathrm{~mm}$, and the standard deviation was $59.35 \mathrm{~mm}$. regarding human operator, the maximum lateral error was $70 \mathrm{~mm}$, average lateral error was $14.75 \mathrm{~mm}$ and standard deviation was $47.86 \mathrm{~mm}$. The performance here was similar to that of the offset discontinuity with normal operation seen leading up to the angle of the path established at 11 $\mathrm{m}$ in to the trial (Table 2). The important observation to make from the final two discontinuity situations was the fact that the system was able to control the disturbance, and continue along the path. Repeated discontinuities could cause problems, but the system was not easily lost by a single expected change in its path, same results were obtained by Spencer (2004).

\subsection{Evaluation the image processing technique}

\subsubsection{Effect of resolution and height of the camera on image processing time}

Image processing time (execution time) is critical and important to determine the speed of ARP, the total time for execution has been noted and recorded under four different camera resolutions $(1080 \times 1920$, $1944 \times 2592,2736 \times 3648$, and $3240 \times 4320$ pixels) and three camera' heights (500, 700 and $1000 \mathrm{~mm}$ ). However, total execution time can not be recorded as one time, but, it includes many times specified to different steps, an example for different steps and their times which are included in the execution process for using camera resolution of 3240×4320 pixel and camera height $1 \mathrm{~m}$ are presented in Table 3. Data showed that with $3240 \times 4320$ pixels as camera resolution, the highest value for the execution time was $2.143 \mathrm{~s}$ when camera used at $1000 \mathrm{~mm}$ height. Greatly, the values of execution time can be in a descending order under all resolutions of $4320 \times 3240,3648 \times 2736,2592 \times 1944$ and $1920 \times 1080$ pixels for camera height of 1000,700 and $500 \mathrm{~mm}$. It could be concluded that the best execution time of image processing was obtained at the minimum values of the camera resolution at $500 \mathrm{~mm}$ camera height (Figure 16) 

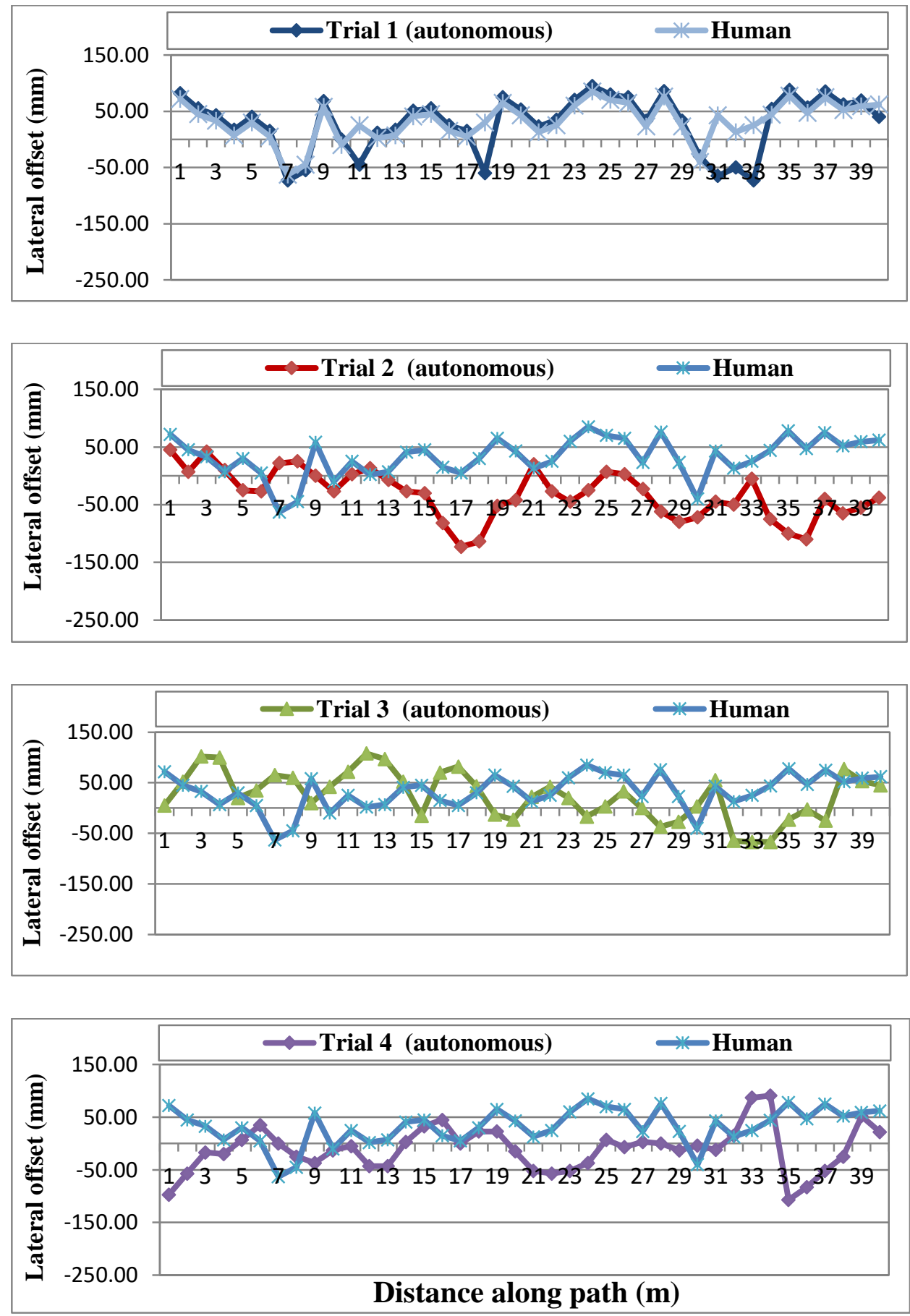

Figure 14: Measured and estimated deviation from the straight path 

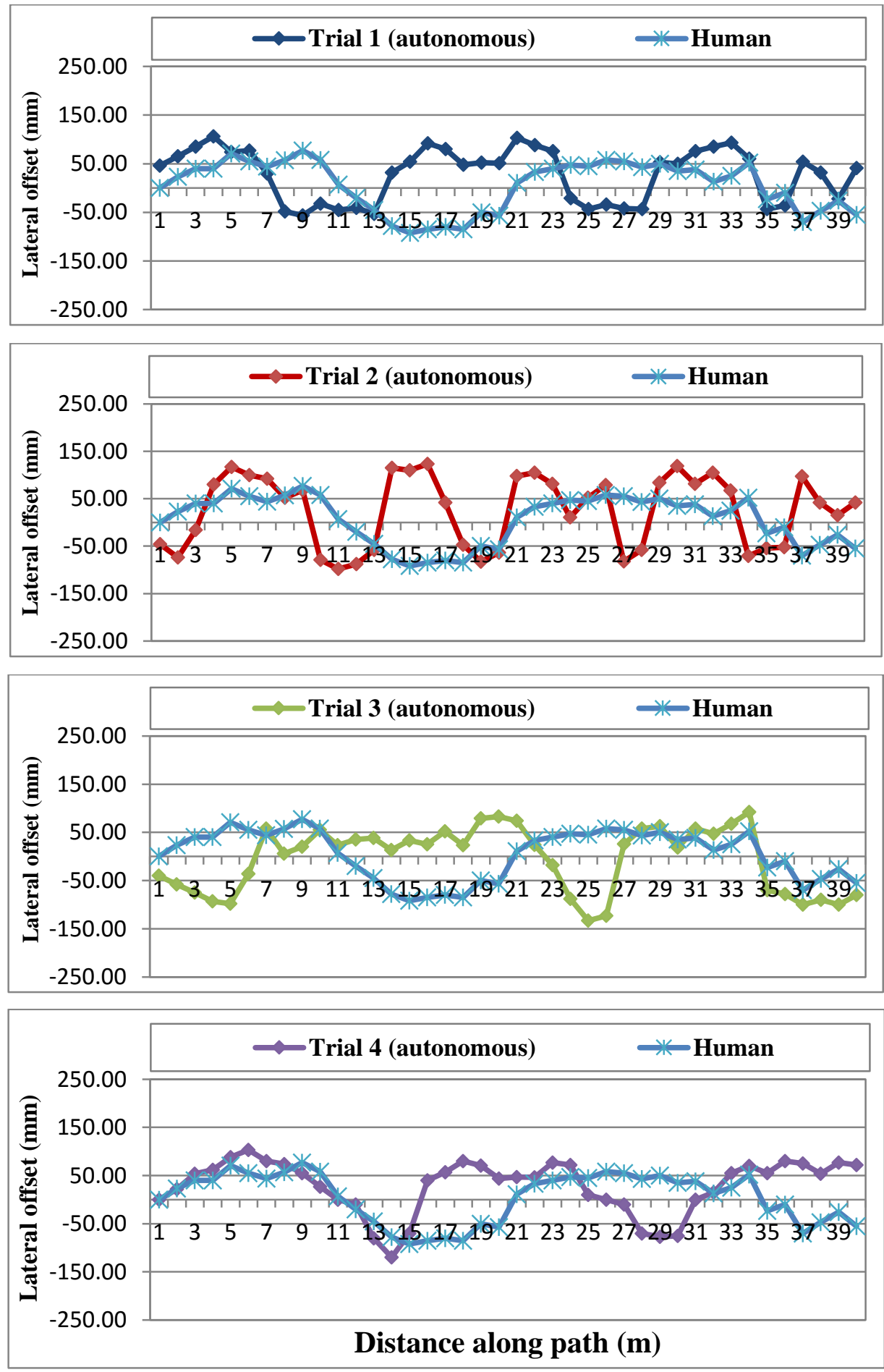

Figure 15: Measured and estimated deviation from the curved line situation 
Table 3: Execution time and its components for image processing steps at resolution $4320 \times 3240$ pixels and camera height $1 \mathrm{~m}$.

\begin{tabular}{|l|c|c|}
\hline Image processing steps & Execution time, $\mathbf{s}$ & $\begin{array}{c}\text { Percent of Total time, } \\
\text { \% }\end{array}$ \\
\hline Prepare image acquisition & 0.02 & 0.93 \\
\hline Smooth images prior & 0.466 & 21.75 \\
\hline The RGB Filter & 0.219 & 10.22 \\
\hline Threshold value of color & 0.614 & 28.65 \\
\hline Threshold value (size) & 0.358 & 16.71 \\
\hline Border module extracts & 0.099 & 4.62 \\
\hline Detection module & 0.026 & 1.21 \\
\hline Hough transform module & 0.104 & 4.85 \\
\hline Module for source current & 0.197 & 9.19 \\
\hline Serial communication & 0.02 & 0.93 \\
\hline Display variable & 0.01 & 0.47 \\
\hline $\begin{array}{l}\text { Visual Basic scripts } \\
\text { module }\end{array}$ & 0.01 & 0.47 \\
\hline Total & $\mathbf{2 . 1 4 3}$ & $\mathbf{1 0 0 \%}$ \\
\hline
\end{tabular}

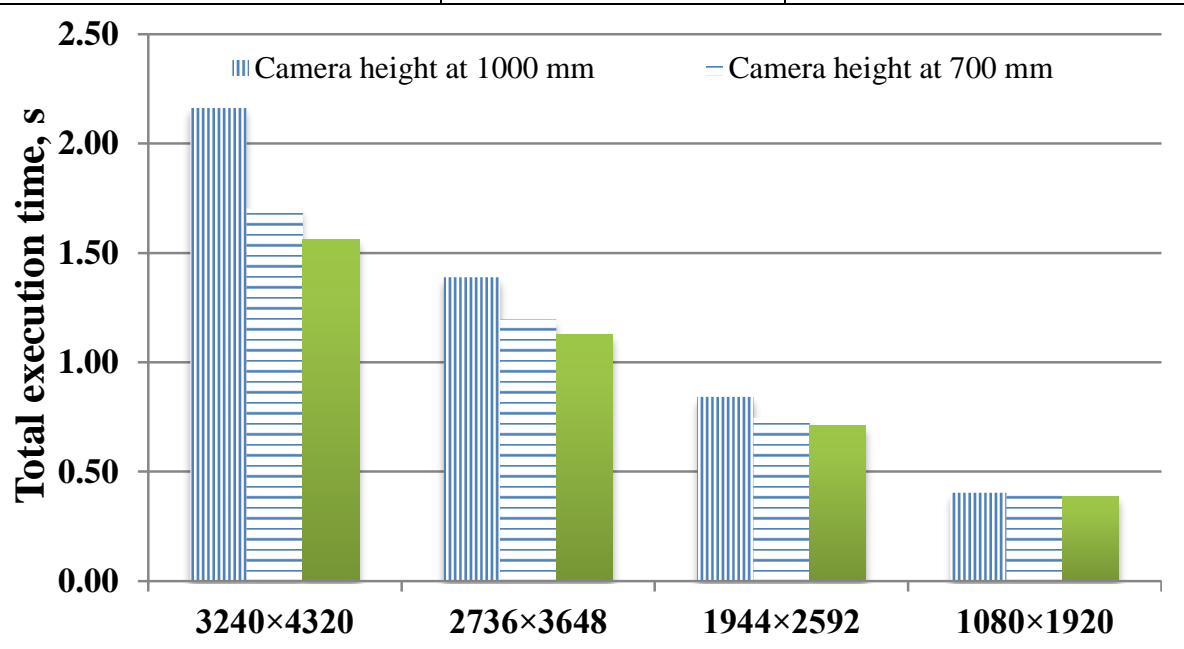

Camera resolution, pixel

Figure 16: Total execution time for image processing steps at different resolution and height of camera.

\subsubsection{Factors affecting the flight time of spray droplet}

Data presented in Figure 17 clearly illustrate the effect of spray height, spray pressure and nozzle size on the flight time of spray droplet from the 
nozzle till plant surface. It was clear that increasing spraying height increase the flight time, where it increased from 12.24 to $16.78 \mathrm{~ms}$ and from 16.78 to $21.1 \mathrm{~ms}$ when the spraying height increased from 70 to 100 $\mathrm{mm}$ and from 100 to $130 \mathrm{~mm}$ respectively at 1 bar spraying pressure and $1.5 \mathrm{~mm}$ nozzle size. Same trend obtained for 3 and bar of spraying pressure.

Increasing the size of nozzle at same height and pressure increased the volume and speed of droplet toward plant surface and accordingly flight time decreased, the data showed that increasing the nozzle size from 1.5 to $3 \mathrm{~mm}$ and from 3 to $5 \mathrm{~mm}$ decreased the flight time by 14 and $9.2 \%$ respectively at $70 \mathrm{~mm}$ spraying height. Same trend obtained for the two other spraying heights.

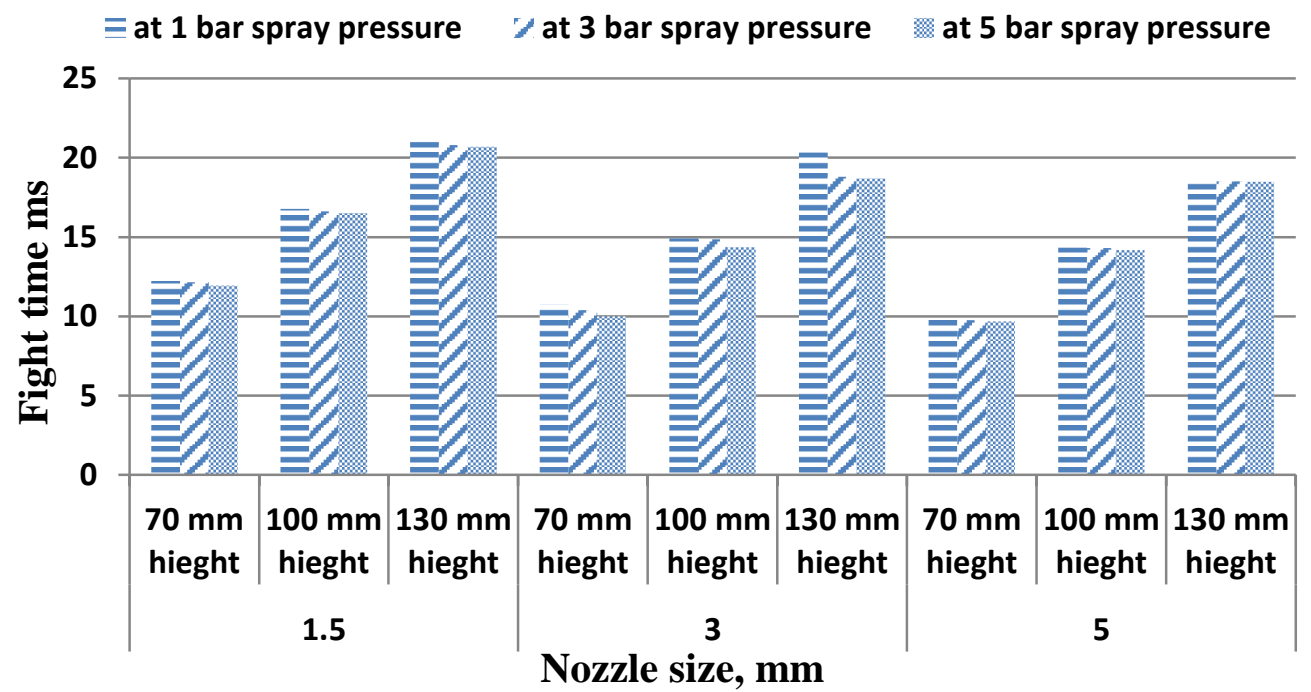

Figure 17: Effect of spray height and nozzle size on the flight time of spray droplet at different spray pressure.

\subsubsection{Effect of duty cycle percentage (DC \%) and frequencies on some performance characteristic of the ARP}

Pulse Width Modulation (PWM) signals were used to control speed of the ARP making possible changing of voltage at frequency $500 \mathrm{~Hz}$. The PWM duty cycle was defined as on/off (\%) in one period. Changing the duty cycle of the PWM signals controlled the open time of DC motor, and thus 
altered its speed and voltage. Data in Table 4 and indicated that the duty cycle greatly affected measured.

Table 4: Effect of duty cycle percentage (DC, \%) and frequencies on calculated voltage, measured voltage, speed motor (RPM) and velocity $\mathbf{m} / \mathbf{s}$.

\begin{tabular}{|c|c|c|c|c|c|}
\hline $\begin{array}{c}\text { Duty } \\
\text { cycle, \% }\end{array}$ & $\begin{array}{c}\text { Calculated } \\
\text { voltage, }\end{array}$ & $\begin{array}{c}\text { Measured } \\
\text { voltage, } \mathbf{v}\end{array}$ & $\begin{array}{c}\text { Speed } \\
\text { motor } \\
\text { (RPM) }\end{array}$ & $\begin{array}{c}\text { velocity } \\
\mathbf{m} / \mathbf{s}\end{array}$ & $\begin{array}{c}\text { velocity } \\
\mathbf{k m} / \mathbf{h}\end{array}$ \\
\hline 10.00 & 1.20 & 2.80 & 436.22 & 0.18 & 0.64 \\
\hline 20.00 & 2.40 & 3.20 & 865.06 & 0.35 & 1.28 \\
\hline 30.00 & 3.60 & 4.30 & 1316.08 & 0.54 & 1.94 \\
\hline 40.00 & 4.80 & 6.20 & 1744.91 & 0.72 & 2.57 \\
\hline 50.00 & 6.00 & 7.70 & 2144.17 & 0.88 & 3.16 \\
\hline 60.00 & 7.20 & 9.10 & 2550.83 & 1.05 & 3.76 \\
\hline 70.00 & 8.40 & 10.00 & 2942.69 & 1.21 & 4.34 \\
\hline 80.00 & 9.60 & 10.60 & 3304.99 & 1.35 & 4.88 \\
\hline 90.00 & 10.80 & 11.70 & 3600.73 & 1.48 & 5.31 \\
\hline 100.00 & 12.00 & 12.00 & 4000.00 & 1.64 & 5.90 \\
\hline
\end{tabular}

\subsubsection{Effect of spray pressure and nozzle tip size on the spray flow rate of the ARP}

From results, it was clear that increase both spray pressure and nozzle tip size tended to increase the average flow rate under study. The increment percentages in average flow rate due to increasing spray pressure from 1 to 3 bar, and from 3 to 5 bar, were 42.69 and $21.63 \%$ respectively when using nozzle tip size of $5 \mathrm{~mm}$. While it increased by 53.92 and $27.61 \%$ respectively by using nozzle size of $3 \mathrm{~mm}$. The corresponding values when using nozzle size $1.5 \mathrm{~mm}$ were 43.39 and $22.92 \%$, respectively. It could be concluded that the increment rate in flow rate was decreased by increasing spray pressure as shown Figure 18.

Also, increasing the size of nozzle from 1.5 to 3 to $5 \mathrm{~mm}$ gave an increment percentage in average flow rates. The increment percentages in sprayer flow rate were $32.68,45.20$ and $48.54 \%$ due to increase the 
nozzle size from 1.5 to $3 \mathrm{~mm}$ under 1,3 and 4.5 bar of spray pressure respectively. However, the increase percentages were 55.96, 45.23 and $40.70 \%$ by increasing the nozzle size from 3 to 5 under 1,3 and 4.5 bar of spray pressure respectively.

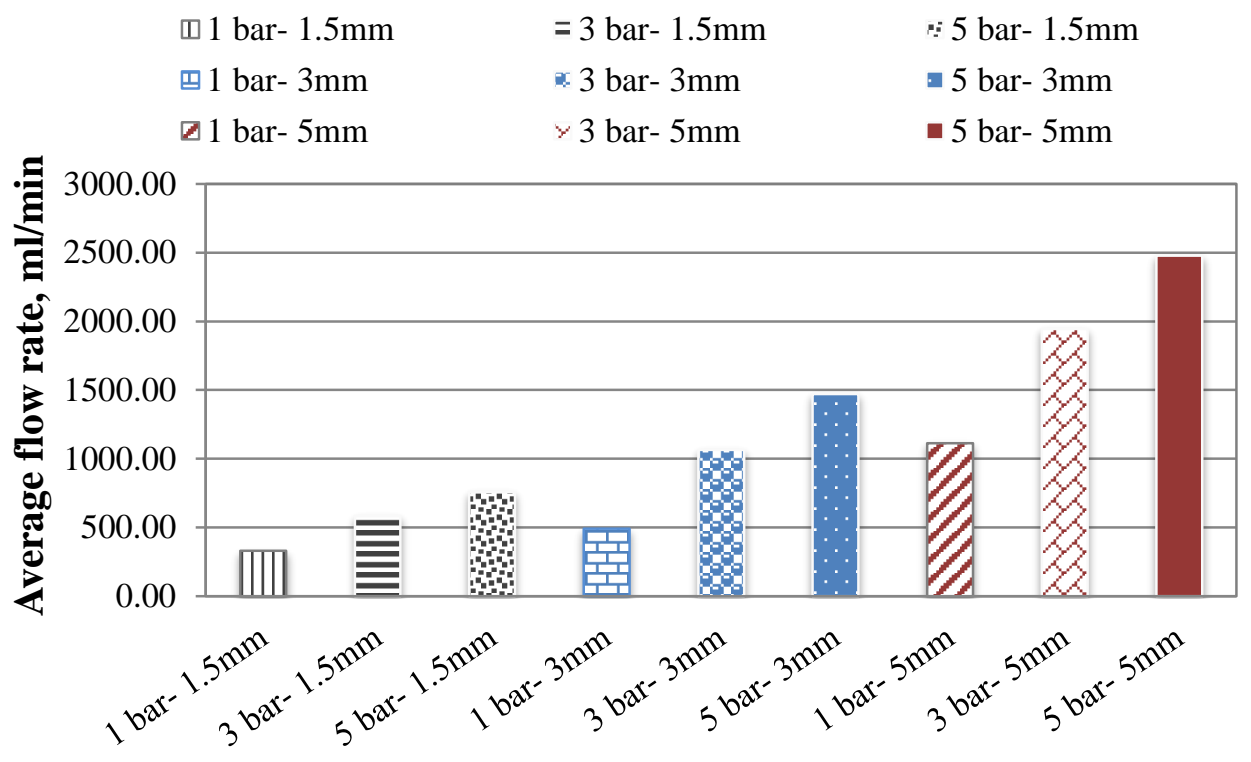

Spray pressure, nozzle size

Figure 18: Effect of spray pressure and nozzle size on the average nozzle flow rate, $\mathrm{ml} / \mathrm{min}$.

1.2.5 Effect of camera resolution, camera height and distance between nozzle and camera on the speed of the ARP.

Results showed that the maximum obtained value of ARP speed was found to be $7.10 \mathrm{~km} / \mathrm{h}$ at the resolution of camera $1080 \times 1920$ pixel, camera height of $700 \mathrm{~mm}$ and $1000 \mathrm{~mm}$ distances between nozzle and camera. While the minimum speed value was $0.40 \mathrm{~km} / \mathrm{h}$ at resolution of camera $3240 \times 4320$ pixel under distances between nozzle and camera of $250 \mathrm{~mm}$ and camera height of $100 \cdot \mathrm{mm}$. It could be concluded that the favorable robotic platform' speeds were obtained at the lower values of camera resolutions and wider distances between nozzle and camera (Table 5). 
Table 5: Effect of camera resolution, camera height and distance between nozzle and camera on the ARP speed.

\begin{tabular}{|c|c|c|c|c|c|}
\hline \multirow{3}{*}{$\begin{array}{c}\text { Camera } \\
\text { accuracy, pixel }\end{array}$} & \multirow{2}{*}{$\begin{array}{c}\text { Camera height, } \\
\text { mm }\end{array}$} & \multicolumn{4}{|c|}{ Distance between nozzle and camera, $\mathbf{m m}$} \\
\hline & & 250 & 500 & 750 & 1000 \\
\hline & \multicolumn{5}{|c|}{ ARP speed. km/h } \\
\hline \multirow{3}{*}{$3240 \times 4320$} & 1000 & 0.40 & 0.79 & 1.19 & 1.58 \\
\hline & 700 & 0.50 & 0.99 & 1.49 & 1.98 \\
\hline & 500 & 0.54 & 1.07 & 1.61 & 2.15 \\
\hline \multirow{3}{*}{$2736 \times 3648$} & 1000 & 0.60 & 1.20 & 1.80 & 2.39 \\
\hline & 700 & 0.69 & 1.38 & 2.07 & 2.76 \\
\hline & 500 & 0.68 & 1.37 & 2.05 & 2.38 \\
\hline \multirow{3}{*}{$1944 \times 2592$} & 1000 & 0.94 & 1.88 & 2.82 & 3.77 \\
\hline & 700 & 1.05 & 2.10 & 3.15 & 4.20 \\
\hline & 500 & 0.97 & 1.93 & 2.90 & 3.51 \\
\hline \multirow{3}{*}{$1080 \times 1920$} & 1000 & 1.73 & 3.47 & 5.20 & 6.93 \\
\hline & 700 & 1.78 & 3.55 & 5.33 & 7.10 \\
\hline & 500 & 1.51 & 3.01 & 4.52 & 5.67 \\
\hline
\end{tabular}

\section{CONCLUSION}

An autonomous robotic platform based on machine vision has been developed and constructed to be implemented in Egyptian conditions as self-propelled mobile vehicle for carrying tools for inter/intra-row crop management based on different control modules. The results showed that performance of the entire autonomous system along a line indicates the machine vision proficiency in determining the location of that line. In each situation (path), the machine vision system was able to adequately distinguish the path and resist image noise. Image processing time mainly depends on resolution height of the used camera; however, using low resolution in processed images is favorable to reduce the execution time. Also, closed distances for camera over the objects (plants) are not recommended. Spray height, spray pressure and nozzle size are affecting the flight time of spray droplet from the nozzle till plant surface, where , bigger nozzle tip size, higher pressure and lower distances were better variables in this study. Duty cycle percentage, camera resolution, camera height and distance between nozzle and camera are critical and important variables to determine the speed of ARP. 


\section{REFERENCES}

ASAE Standard (1998). Calibration and Distribution Pattern Testing of Agriculture Arial Application Equipment. Ag. Eng., yearbook: pp.244-247.

Astrand B. and A. J. Baerveldt (2005). A vision based row-following system for agricultural machinery. Mechatronics, 15(2): 251-269.

Ayala, M.; C. Soria and R. Carelli (2008). Visual servo control of a mobile robot in agriculture environments, Mechanics Based Design of Structures and Machines, 36: 392-410.

Barawid Jr, O.; A. Mizushima; K. Ishii and N. Noguchi (2007). Development of an autonomous navigation system using a twodimensional laser scanner in an orchard application, Biosystems Engineering, 96: 139-149.

Blackmore, B. S.; H. Griepentrog; S. Fountas and T. Gemtos (2007). A Specification for an autonomous crop production mechanization system. Agric Eng Int: CIGR Ejournal; 9:6-32.

Blasco, J.; N. Aleixos; J. M. Roger; G. Rabatel and E. Molto (2002). Robotic weed control using machine vision. Biosystems Engineering, 83(2), 149-157.

Cho, S. I.; D. S. Lee and J. Y. Jeong (2002). Weed-plant discrimination by machine vision and artificial neural network. Biosystems Eng 82(3): 275-280.

Forsyth, D. A. and J. Ponce (2003). Computer Vision- A modern approach. Prentice-Hall, New Jersey.

Gao, F.; Y. Xun; J. Wu; G. Bao and Y. Tan (2010). Navigation line detection based on robotic vision in natural vegetation-embraced environment, 2010 3rd International Congress on Image and Signal Processing (CISP) p. 2596-2600.

Hamner, B.; S. Singh and M. Bergerman (2010). Improving orchard efficiency with autonomous utility vehicles, 2010 ASABE Annual International Meeting, Pittsburgh, PA, Paper Number 1009415. 
Hloben, P. (2007). Study on the response time of direct injection systems for variable rate application of herbicides. Ph. D. Thesis. Bonn University, Germany.

Ji, R. and L. Qi (2011). Crop-row detection algorithm based on random Hough transformation. Mathematical and Computer Modelling, 54, 1016-1020.

Kiani, S. and A. Jafari (2012). Crop Detection and Positioning in the Field Using Discriminant Analysis and Neural Networks Based on Shape Features, J. Agr. Sci. Tech. Vol. 14: 755-765

Lee, W. S. (1998). Robotic weed control system for tomatoes. Ph.D. thesis, University of California, USA.

Meyer, G. E. and J. C. Neto. (2008). Verification of color vegetation indices for automated crop imaging applications. Computer and electronics in agriculture 63(2): 282-293.

Patel, K. B.; M. B. Zalte and S. R. Panchal (2013). A Review: Machine vision and its Applications. Journal of Electronics and Communication Engineering (IOSR-JECE), Vol. 7 (5): 72-77.

Sick ivp (2006). Machine vision introduction. Version 2.2 https://www.sick.com/medias/Machine-Vision-Introduction2-2web.pdf.

Spencer, S. R. (2004). Development of an Autonomous Vehicle for use in Agriculture. M. Sc. Thesis, Biological engineering Department. The Graduate Faculty of North Carolina State University.

Subramanian, V. (2005). Autonomous vehicle guidance using machine vision and laser radar for agricultural applications. M. Sc. Thesis. Agricultural and Biological Engineering Department. University of Florida, U.S.A.

Torres-Sospedra, J. and P. Nebot (2011). A new approach to visualbased sensory system for navigation into orange groves, Sensors, 11: 4086-4103.

Xue, J.; L. Zhang and T. E. Grift (2012). Variable field-of-view machine vision based row guidance of an agricultural robot. Computers and Electronics in Agriculture, 84: 85-91. 


\section{الملخص العربي}

\section{تطوير رويوت زراعى للابحار الذاتى الحركة اعتمادا على الروئية الالية}

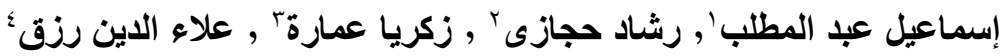

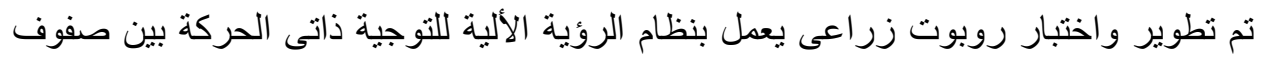

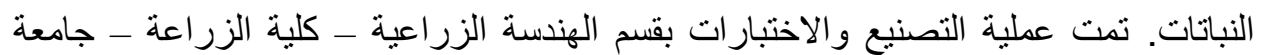

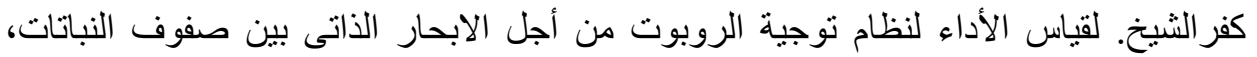

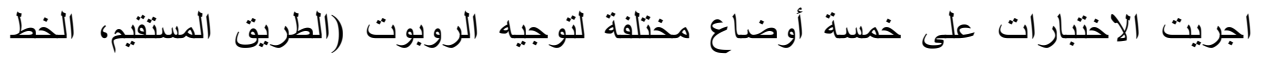

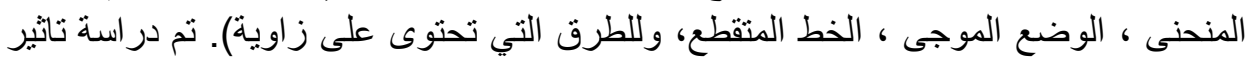

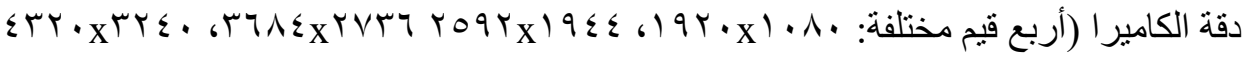

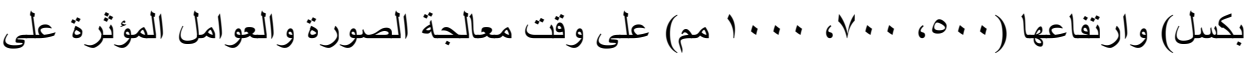

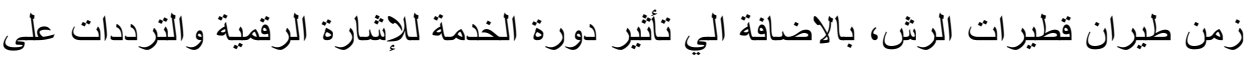
بعض خصائص الاداء للروبوت الزراعى وكذللك در اسة تأثير ضغط الرش و اقطار فورة هات الرش على معدل تدفق الرش.

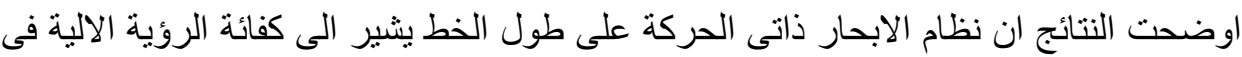

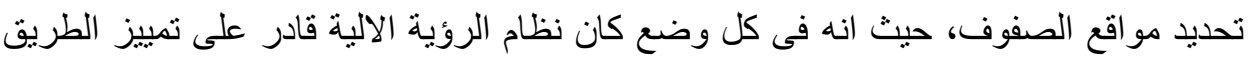

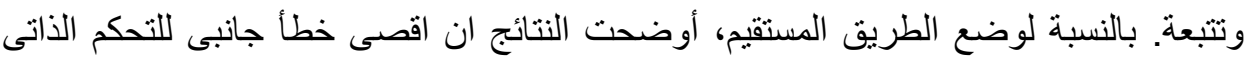
كان

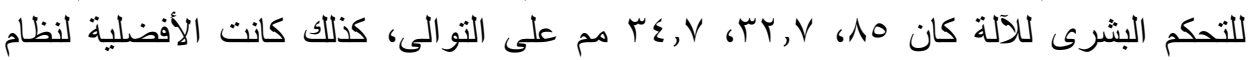

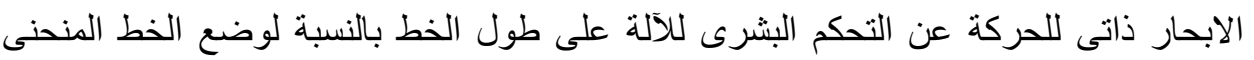
ووضع الموجى والخط المتقطع وللطرق التي تحتوى على زاوية. أوضحت البيانات ايضاً ان

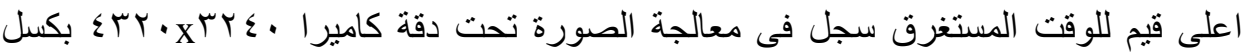

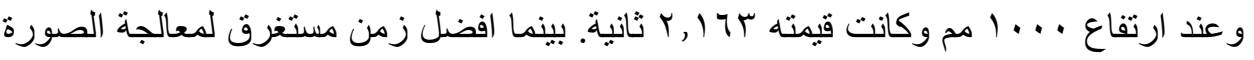

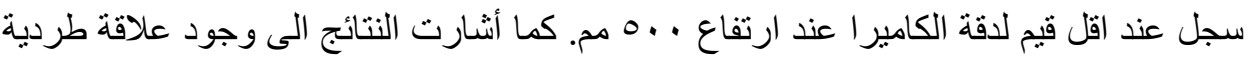

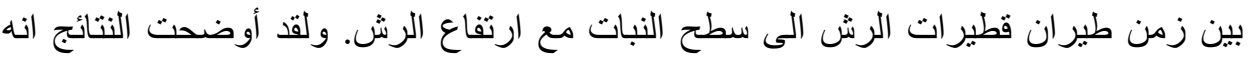

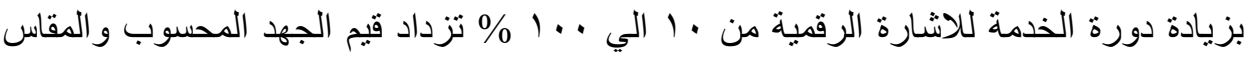

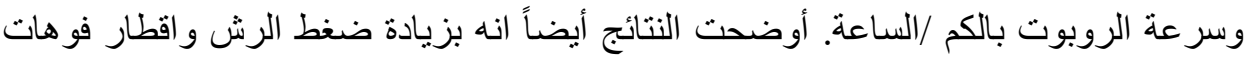

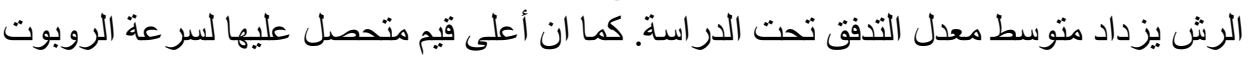

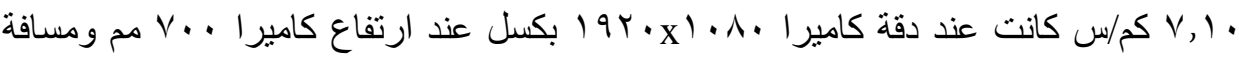

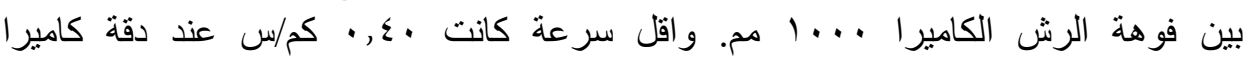
• .

ا ـ أستاذ الهندسة الزراعية ـ بكلية الزراعةـ جامعة كفر الشيخ.

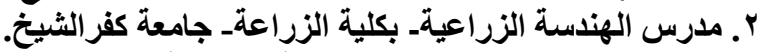

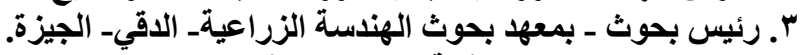

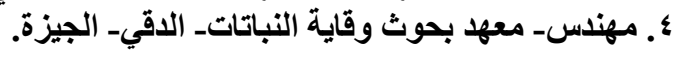

